\title{
Strengthening and Stabilization of the Weak Water Saturated Soils Using Stone Columns
}

\author{
Leonid Sinyakov ${ }^{1}$, Grigory Garmanov ${ }^{1, *}$ and Alexey Melentev ${ }^{1}$ \\ ${ }^{1}$ Peter the Great St. Petersburg Polytechnic University, 195251, Polytechnicheskaya 29, St. \\ Petersburg, Russia
}

\begin{abstract}
The article considers innovative modern materials and structures for strengthening of weak soils. In this paper describes a method of strengthening of weak saturated soils using stone columns. The method of calculating the physical-mechanical characteristics of reinforced soil mass is presented. Two approaches to determining the stress-strain state and timeframe of consolidation of strengthened soil foundation using the finite element technique in two-dimensional formulation are proposed. The first one approach it is a modeling of reinforced soil mass, where each pile is represented as a separate $2 \mathrm{D}$ stripe. The second approach is to the simulation of the strengthened mass the equivalent composite block with improved physical-mechanical characteristics. The use of the equivalent composite block can significantly reduce the time spent on the preparation of a design scheme. The results of calculations were compared. They show the allowable divergence of results of calculation by two methods were presented, and the efficiency of the strengthening of weak water saturated soils by stone column is proved.
\end{abstract}

\section{Introduction}

Weak saturated soil in the foundation of building or structure is one of the most serious problems encountered in the design process. Very important role is played by the correct and possibly more accurate assessment of the impact of weak soil mass for the designed object. Concerning special attention should be also paid to engineering and geological surveys on construction site. Low strength characteristics, strong compressibility and the long duration of building sediment are the key features that must be taken into consideration when buildings on weak saturated soils (especially clay soils) are projected.

Most often weak saturated soil cannot be used as grounds for buildings and structures without prior measures to strengthen the soil mass. From the correctness of the chosen and developed method of strengthening depends on the further process of the construction and operation of the designed object because inaccuracies may lead to significant deformations of the ground and hence malfunction of the building structure and emergencies.

\footnotetext{
Corresponding author: gri.garmanov@gmail.com
} 
During the existence of this problem, various methods have been developed in order to solve it: the arrangement of sandy pillows, the replacement of weak soils, the arrangement of sandy piles and different drains with loading mound, fixing of soil by using jet grouting. All the methods have their own characteristics and applicability [1-11].

The paper considers in detail the variant of strengthening of weak saturated soils by modern progressive method of arrangement of soil stone columns what increases strength characteristics of soil mass and also the piles function as drains that greatly accelerates the process of consolidation of the foundation and passing the predicted sediment. This method is not very common today in Russia and a recommendation that regulates use of the stone columns is missing in the normative base. That's why the one of the aim of this paper is the presentation of the method of calculation of physical-mechanical characteristics of the soil. The technique produced using the international experience of employment of the stone columns arrangement technology for strengthening weak grounds [12-15].

\section{The technology of arrangement of stone columns}

Stone columns are the soil piles which are set through weak layers of soil in order to sealing and transfer loadings on the more strong layers of soil. The piles are formed by immersing in a ground vibration sonde and submission of crushed stone in formed well. Crushed stone substitutes for weak ground, displacing and compacting it, resulting in a significant improvement in strength and deformation characteristics of the soil mass within which the strengthening is carried out.

Also the stone columns work just like normal ground drains resulting in significant reduce of timeframe of consolidation when saturated clay soils lie in the foundation of future building.

This technology is well suited for improving the characteristics of the soil mass, folded by these types of soils like sands, sandy loams, loams and clays.

The technological process of stone columns arrangement consists of the following steps:

the deep vibrator is immersed with the help of vibration and air. If necessary, the deep vibrator is immersed with a minimum flow of water under pressure for passage of the dense layers (Fig. 1, I);

crushed stone is injected through a special drive along the vibrator under the pressure of compressed air (Fig. 1, II);

the deep vibrator is doing reciprocating motion that compacting the crushed stone and gradually forms the body of the pile while moving up (Fig. 1, III).
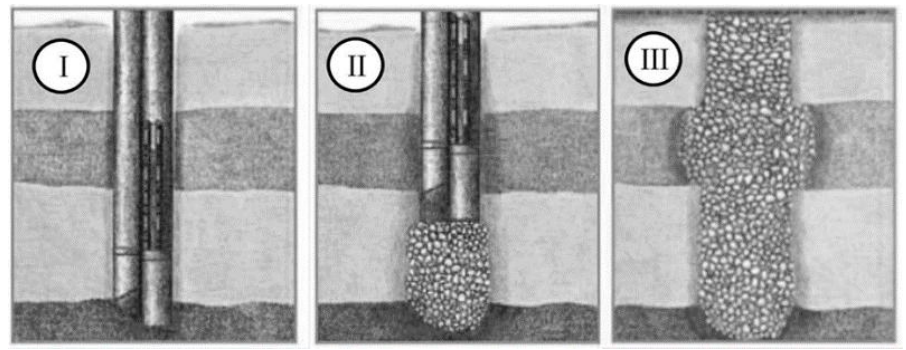

Fig. 1. The sequence of the arrangement stone columns

When the arrangement of stone columns is taken place, the special equipment, so-called vibro-probe - deep vibrator, is used (Fig. 2), and the type of vibro-probe is selected depending on the task. For supplying sealing material under the lower end of the equipment, a special drive is mounted to vibrator. 

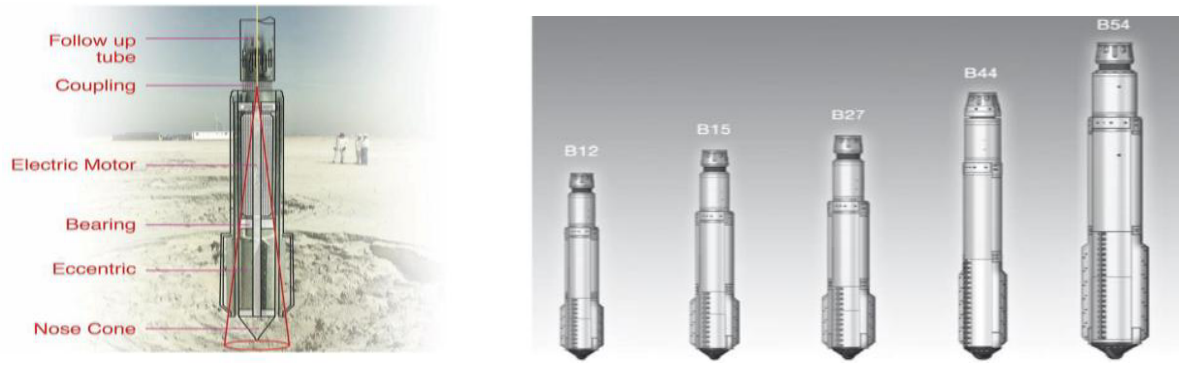

Fig. 2. Vibro-probes

The substructure located on the ground that is strengthened by stone columns should be considered as the foundation on a soil condition taking into consideration physicalmechanical characteristics of a strengthened soil mass.

\section{Solution of the problem}

Physical and mechanical characteristics of strengthened soil mass are calculated as converted characteristics of natural soil taking into consideration the volume fraction of the stone columns in the soil mass [15].

The determination of the coefficient of internal friction of strengthened soil mass $\tan \bar{\varphi}$, and its specific weight $-\bar{\gamma}$ of strengthened soil mass is carried out with usage of formulas that are given below:

$$
\begin{aligned}
& \tan \bar{\varphi}=m^{\prime} \cdot \tan \varphi_{C}+\left(1-m^{\prime}\right) \tan \varphi_{s}, \\
& \bar{\gamma}=m^{\prime} \cdot \gamma_{c}+\left(1-m^{\prime}\right) \gamma_{s},
\end{aligned}
$$

where, $\varphi_{c}$ - the angle of internal friction of the stone column material;

$\varphi_{S}$ - the angle of internal friction of the soil

$\gamma_{c}$ - the specific weight of the stone column material;

$\gamma_{s}$ - the specific weight of the soil;

$m^{\prime}$ - the proportional parameter, that is defined by the formula (3):

$$
m^{\prime}=(n-1) / n,
$$

where, $\mathrm{n}$ - strengthening coefficient, that is calculated based on the ratio of the squares of stone columns and the strengthened soil mass and defined by the formula (4):

$$
n=1+\frac{A_{C}}{A} \cdot\left[\frac{5-A_{C} / A}{4 K_{a C} \cdot\left(1-A_{C} / A\right)}-1\right],
$$

where, $A_{c}$ - the cross-sectional area of the stone column;

$A$ - the area of influence of the stone column; 
$K_{a C}$ - the coefficient of active pressure of the stone columns material, defined by the formula (5):

$$
K_{a C}=\tan ^{2}\left(45^{\circ}-\varphi_{C} / 2\right)
$$

The determination of the adhesion of the of strengthened soil mass $\bar{c}$ is defined by the formula (6), that is given below:

$$
\bar{c}=\frac{\left(A-A_{c}\right) \cdot c_{s}}{A}
$$

where $c_{s}$-specified soil adhesion, $A$ and $A_{c}$ - the same thing like the parameters in the formula (5).

\section{Example.}

In the given example, the calculation of the ground of a road embankment performed. The construction of the embankment is considered as stable with the following characteristics: the deformation module (E) - $30 \mathrm{MPa}$, the angle of internal friction -30 degrees, the specified adhesion $-1 \mathrm{kPa}$, the specified weight $-18 \mathrm{kN} / \mathrm{m} 3$.

The ground of the road embankment is folded by slowly compacting saturated soil that is clayey silt with the following characteristics: the deformation module $(\mathrm{E})-1 \mathrm{MPa}$, the angle of internal friction -2 degrees, the specified adhesion $-12 \mathrm{kPa}$, the specified weight $-14 \mathrm{kN} / \mathrm{m} 3$.

The unpleasant condition of clay soils that are presented in the ground should be noted. The presented sediments have low strength and deformation characteristics and low filtration options and are characterized by a long term seal. The presence of so weak soil in the foundation can leads to long term stabilization of deformations during many years, as well as to uneven deformation during exploitation.

The conversion of building properties of the soil is reached by creation of stone columns with a diameter of 1.2 meters that are arrange to the entire depth of the occurrence of organic soils.

The characteristics of the material of stone columns are the following: the deformation module (E) - $40 \mathrm{MPa}$, the angle of internal friction -40 degrees, the specified adhesion -1 $\mathrm{kPa}$, the specified weight $-20 \mathrm{kN} / \mathrm{m} 3$.

The calculated physical-mechanical characteristics of the strengthened soil mass is calculated according to the formulas (1-6) and are provided in Tab. 1.

Table 1. The calculated physical-mechanical characteristics of the strengthened soil mass

\begin{tabular}{|c|c|c|c|c|c|c|}
\hline Title & Column diameter, $[\mathrm{m}]$ & $\begin{array}{c}\text { Area of } \\
\text { the } \\
\text { column, } \\
{\left[\mathrm{m}^{2}\right]}\end{array}$ & $\begin{array}{c}\text { Area of } \\
\text { the } \\
\text { influence, } \\
{\left[\mathrm{m}^{2}\right]}\end{array}$ & $\begin{array}{c}\bar{\gamma}, \\
{\left[\mathrm{kN} / \mathrm{m}^{3}\right]}\end{array}$ & $\begin{array}{c}\overline{\mathrm{c}}, \\
{[\mathrm{kPa}]}\end{array}$ & $\begin{array}{c}\bar{\varphi}, \\
{[\mathrm{deg} .]}\end{array}$ \\
\hline $\begin{array}{c}\text { Strengthened } \\
\text { mass }\end{array}$ & 1.2 & 1.130 & 4.98 & 17.6 & 7.7 & 27.8 \\
\hline
\end{tabular}

In order to determine the deformation module of the strengthened soil mass when stone column are arranged the series of tests was carried out using the finite element method in three-dimensional statement by means of software package Plaxis 3D (Fig. 3). 

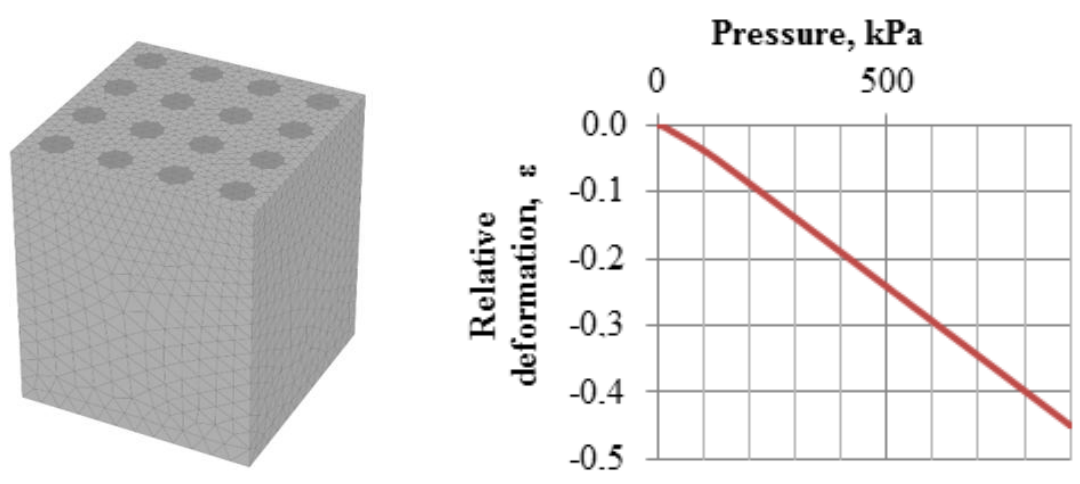

Fig. 3. The general view of the design scheme and the graph of the relative deformation and pressure for the soil mass strengthened by stone columns with a diameter of $1.2 \mathrm{~m}$ and a step of $1.9 \times 2.4 \mathrm{~m}$ (conditionally the load not shown)

According to the results of calculation the odometer module of deformation of strengthened soil mass is $\mathrm{E}_{\text {oed }}=1.95 \mathrm{MPa} \mathrm{MPa}$.

During the research process the calculations of subsidence of the mounds and timeframes of consolidation of the soil ground were carried out for the following design schemes:

1) Analysis 1 - 2D FEA without strengthening;

2) Analysis 2-2D plane strain FEA with the stone columns modeled as strips (Fig. 4, a);

3)Analysis 3 - 2D FEA with the soil and columns modeled as equivalent composite block (Fig. 4, b).

The calculations carried out by means of software package Plaxis 2D with using MohrCoulomb model.

a)

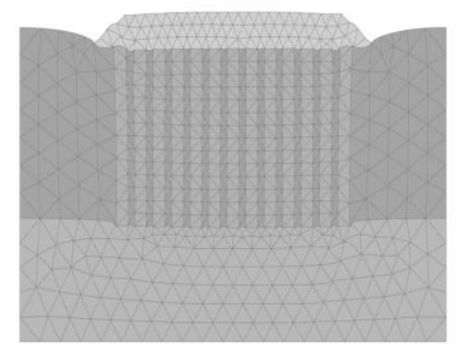

Deformed mesh |u| (scaled up 20.0 times)

Maximum value $=0.08393 \mathrm{~m}$ (Element 774 at Node 3462) b)

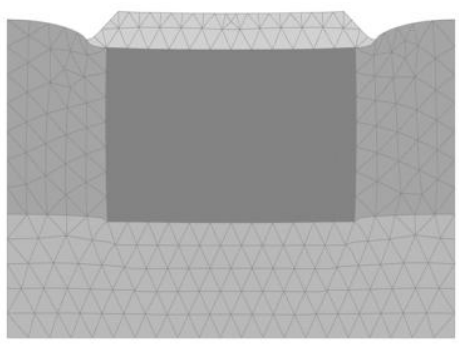

Deformed mesh $|u|$ (scaled up 20.0 times)

Maximum value $=0.09445 \mathrm{~m}$ (Element 475 at Node 2323)

Fig. 4. Embankment deformations schemes

a) FEA with equivalent stone column strips (Analysis 2) b) FEA (Analysis 3) with equivalent composite block 
The results of comparative calculations are shown in Tab. 2.

Table 2. Calculation results

\begin{tabular}{|l|c|c|c|}
\hline \multicolumn{1}{|c|}{ Title } & $\begin{array}{c}\text { Without } \\
\text { strengthening } \\
\text { (Analysis 1) }\end{array}$ & $\begin{array}{c}\text { With } \\
\text { strengthening } \\
\text { (Analysis 2) }\end{array}$ & $\begin{array}{c}\text { With } \\
\text { strengthening } \\
\text { (Analysis 3) }\end{array}$ \\
\hline $\begin{array}{l}\text { Subsidence of the } \\
\text { embankment, [cm] }\end{array}$ & 32.04 & 8.40 & 9.44 \\
\hline $\begin{array}{l}\text { Time of consolidation, } \\
\text { [days] }\end{array}$ & 258 & 35 & 38 \\
\hline
\end{tabular}

As can be seen from the calculation results when the ground is strengthened by arrangement of stone columns, the maximal calculated subsidence was $8.40 \mathrm{~cm}$ when there were dumping at design height, that is much less than the result without strengthening. The timeframe of the stabilization of deformation of the ground was significantly reduced, from 258 to 35 days. The small differences in the results of the calculation for the full (Analysis 2) and the simplified scheme (Analysis 3) should be noted.

\section{Conclusion}

1. On the basis of international experience of using of stone columns arrangement technology for strengthening weak grounds was offers the method of calculation physical-mechanical characteristics of a strengthened soil mass.

2. The example of calculation of a weak soil foundation is given, taking in account strengthening by stone columns.

3. The technique of determining odometer module of deformation of strengthened soil mass is displayed.

4. The comparative calculations showed small differences between using the full and simplified scheme. The use of the simplified scheme setting stone columns by soil mass with physical-mechanical parameters calculated using the proposed formulas sufficiently saves time on generating a design scheme and the PC calculation time.

5. The use of the method of weak soils strengthening using stone columns has the following advantages: the decrease of the deformation values of soil mass in several times; a significant reduction in terms of soil consolidation; increased resistance to liquefaction of weak soils under dynamic loading due to an increase in their density and strength; the use in the construction of transport, industrial, civil and hydraulic structures.

\section{References}

1. SP 22.13330.2011. Soil bases of buildings and structures (Moscow, 2011)

2. SP 24.13330.2011. Pile foundations (Moscow, 2011)

3. M. I. Abelev, Construction of industrial and civil buildings on weak saturated soils (Stroyizdat, Moscow, 1983)

4. R.A. Mangushev, V.D. Karlov, I.I. Sakharov, Soil Mechanics: Textbook (ASV, Moscow, 2009)

5. P.A. Konovalov, Soil bases and foundation of buildings under reconstruction, fourth ed. (VNINTPI, Moscow, 2000)

6. V.A. Ilichev, R.A. Mangushev, Geotechnical manual. Grounds, foundations and underground structures (ASV, Moscow, 2014)

7. A. G. Malinin, Strujnaya tsementatsiya gruntov (Stroyizdat, Moscow, 2010) 
8. A. M. Golovanov, V. I. Pashkov, G.A. Revo, D.V. Pashkov, O. V. Nerchinskij, R. I. Turenko, Vestnik MGSU, 8, 59-67 (2013)

9. B. I. Dalmatov, Proektirovanie fundamentov zdanij I podzemnykh sooruzhenij: Uchebnoe posobie, second ed. (ASV, Moscow, 2001)

10. R.A. Mangushev, Osnovaniya I fundamenty (ASV, Moscow, 2011)

11. S. G. Bogov, Razvitie gorodov I geotekhnicheskoe stoitel'stvo, 2, 1-12 (2000)

12. M. Bouassida, S. Ellouze, Z. Ben Salem, M. N. Znaidi, Foundation and Soft Ground Engineering Conference, 1, 55-66 (2013)

13. J. M. O. Hughes, N. J. Withers, Ground Engineering, 7, $42-49$ (1974)

14. M. R. Shirazi, O. Zarrinkafsh, K. Valipourian, International Journal of Civil, Environmental, Structural, Construction and Architectural Engineering, 9, 601-605 (2015)

15. Heinz J. Priebe, Ground Engineering, 7-13, 1-16 (1995) 